\title{
Pathological and molecular study of ovine diaphragms naturally infected by Sarcosystis spp.
}

\author{
E.S. Mostafa ${ }^{1}$, N.S. Alhayali ${ }^{2}$ and E.G. Suleiman ${ }^{2}$ 'D \\ ${ }^{1}$ Department of Pathology and Poultry Diseases, ${ }^{2}$ Department of Microbiology, College of Veterinary Medicine, University \\ of Mosul, Mosul, Iraq
}

\section{Article information}

Article history:

Received September 9, 2020

Accepted January 23, 2021

Available online October 1, 2021

\begin{tabular}{l}
\hline Keywords: \\
Sarcosystis species \\
Sheep \\
PCR \\
Muscle \\
Sarcosystis tenella
\end{tabular}

Correspondence:

E.S. Mostafa

enas.sheet1@gmail.com

\begin{abstract}
Sarcosystis spp., has a close relationship with muscles due to its unique localization within skeletal muscle in humans and the animals it infects, as the chronic condition of the disease causes significant economic losses, especially in terms of meat production as a result of the formation of cysts, whether macroscopic or microscopic, in their muscle fibers. Sarcosystis tenella and Sarcosystis arieticanis are the most important pathogenic cysts forming in sheep. In this study, 50 samples of diaphragm muscles of sheep slaughtered in the butchers' shops and the Mosul abattoir were examined grossly, histologically, and using PCR technique as a diagnostic tool to identify or diagnose the causative and responsible species of these changes. The diaphragm samples appeared white and pale on the macroscopic examination, while the tissue lesions were characterized by the presence of Sarcosystis in different numbers and sizes among the muscle fibers, which led to the occurrence of zinker necrosis and intense infiltration of inflammatory cells, especially eosinophil, monocyte, macrophage and giant cells, and also oedema and proliferation of fibroblast. With the formation of fibrous tissue whose intensity was inferred (mild, medium and intense) by using the masson's trichrome stain. The results of the molecular analysis using the nested PCR technique indicated that these diagnosed microscopic cysts belong to Sarcosystis tenella with a reaction product of $800 \mathrm{bp}$ and 500bp.
\end{abstract}

DOI: 10.33899/ijvs.2021.128327.1570, (CAuthors, 2021, College of Veterinary Medicine, University of Mosul.

This is an open access article under the CC BY 4.0 license (http://creativecommons.org/licenses/by/4.0/).

\section{Introduction}

Sarcosystis is coccidian parasites related to Apicomplexa phylum, sheep are an intermediate host of for six species, they are: Sarcosystis tenella, Sarcosystis arieticanis, Sarcosystis mihoensis, Sarcosystis microps, Sarcosystis gigantea and Sarcosystis medusiformis (1). The microscopic species $S$. tenella and $S$. arieticanis are consider a most pathogenic species which causes economic losses in sheep (2).

The severity of Sarcosporidiosis depends on the immune status of the host and the dose of sporocysts were ingested which are raised with the feces of the definitive hosts $(3,4)$.
Eosinophilic Myositis (EM) is a general term which used in meat examination to identify diseases in animals clinically appeared healthy with muscle lesions of unknown cause (5).

In Bovine Eosinophilic Myositis (BEM) are a heterogeneous group of muscle disease caused by an autoimmune response, allergic reaction or drugs or by bacterial infection Sarcosystis spp. is consider one of the factors causing this pathology (6).

Although Sarcosystis are well adapted to live in the muscles and central nervous system without any reaction from the host, some Sarcosystis rupture from time to time, producing toxic substances. (7).

The results of several re searchers indicate that Sarcoystis parasite has a direct relationship with EM as it 
contributes to rejection and decrease in carcass quality in meat processing plants (5). One difficulty with Eosinophilic myositis that it cannot be detected in live animals as there are no tests to diagnose or detect this pathology while the animal is alive (8). Generally, EM occurs only in striated muscles and does not appear in internal organs or smooth muscles, and in the case of mild lesions in the carcass the most active muscles are affected, such as muscles of tongue, heart, and diaphragm. In severe cases, all striated muscles are affected (9).

Hence, the aim of our study design to diagnose the pathological changes in the diaphragm muscles of sheep that infected with Sarcosystis and to determine particular microscopic Sarcosystis species that causes the eosinophilic myositis by using molecular techniques.

\section{Materials and methods}

\section{Sample collections}

Diaphragm muscles were collected from butcher shops and abattoirs in Mosul city, Iraq during the period from June - October of 2019, were investigated for Sarcosystis infection. During postmortem inspection of slaughtered animals, tissue samples were isolated from 50 sheep. The samples were collected and stored in plastic bags. Where work was done in the Laboratory of Parasitology, College of Veterinary Medicine, University of Mosul.

\section{Gross examination}

The diaphragm muscles were examined grossly for detecting gross pathological changes.

\section{Microscopic examination}

Unstained samples of diaphragm muscles were examined by light microscope for detection of the microscopic Sarcosystis species $(1,2)$. Approximately 2-3 $\mathrm{mm}^{3}$ of muscles were taken and squashed by two slides and then examined under $40 \mathrm{X}$ objective lens.

\section{Histopathological examination}

Parts of diaphragm muscles from each sample were fixed in $10 \%$ neutral buffer formalin at least 48 hours. The fixed muscles samples were trimmed into $0.5 \mathrm{~cm}^{3}$ thick section dehydrated with serial dilutions of ethanol and xylene, then embedded in paraffin block for sectioned to 3$5 \mathrm{~mm}$, then stained with hematoxylin and eosin (H\&E) and Masson's trichrome examined for detection of microcysts with light microscope (10-12).

\section{Extraction of DNA}

DNA was extracted by using Prime Prep Genomic DNA extraction kit (Genet Bio, Korea). From 11 diaphragm muscle samples following the manufacturer instruction, the DNA pellet was rehydrated by adding $100 \mu$ l of rehydration solution and kept at $-20^{\circ} \mathrm{C}$ until further assay.

\section{Polymerase chain reaction (PCR) assay procedure}

PCR was done to confirm the presence of Sarcosystis tenella and Sarcosystis arieticanis using the primers according to Pipia et al. (13) (Table 1). The PCR reaction mixtures were prepared in $25 \mu \mathrm{l}$ containing $12.5 \mu \mathrm{l}$ of HS Prime Taq Premix (2X) (Genet Bio, Korea) with final concentration of $1 \mathrm{X}, 1 \mu \mathrm{l}$ of each primer and $3 \mu \mathrm{l}$ of DNA template and $7.5 \mu \mathrm{l}$ of PCR grade water. The PCR was done using thermal cycler (T100, Bio-Rad, USA) and PCR cycles were performed as shown in (Table 2-4). The amplified products were separated using electrophoresis in $1.5 \%$ agarose gel (Jena Bioscience, Germany) pertained with $4 \mu \mathrm{l}$ GelSafe (GeNet Bio, Korea). A $4 \mu \mathrm{l}$ of each PCR product was loaded into the well of agarose gel. The electrophoresis was carried out at $80 \mathrm{~V}$ for 1 hour using power supply MP $300 \mathrm{~V}$ (Bio-Rad, USA) containing $1 \mathrm{X}$ TBE buffer (GeNetBio, Korea).

A 100 bp DNA marker, $4 \mu 1$ (Genet Bio, Korea) was used as standard molecular weight marker. The gel was examined under UV light using Gel doc Ez system (BioRad, USA) (13).

Table 1: Sequences of primers used for detection of Sarcosystis tenella using nested PCR

\begin{tabular}{lccc}
\hline No. & Primer Name & Primer Sequence 5' 3 $^{\prime}$ & Type \\
\hline 1. & ST1-F & GGATCGCATTATGGTCAT & External primers \\
2. & AP2-R & CCCGGGATCCAAGCTTGATCCTTCTGCAGGTTCACCTAC & \\
3. & 8-F & TTTGACTCAACACGGG & Nested primers \\
4. & ST3-R & CGTTGCCGCGCGTTAA & \\
\hline
\end{tabular}

Table 2: Sequences of primers used for detection of Sarcosystis arieticanis using nested PCR

\begin{tabular}{lccc}
\hline No. & Primer Name & Primer Sequence 5' $-3^{\prime}$ & Type \\
\hline 1. & STA-F & TTT CGC AAG GAA GAG GA & External primers \\
2. & SA2-R & TGA AAC GGC GCG TAG A & \\
3. & $2-\mathrm{F}$ & AGG GTT CGA TTC CGG AG & Nested primers \\
4. & SA1-R & GCG GGA AGA GGA GAA T & \\
\hline
\end{tabular}


Table 3: Cycling conditions of PCR for amplification of Sarcosystis

\begin{tabular}{lcccc}
\hline No. & Step & Temp & Time & Cycle \\
\hline 1. & Polymerase activation & $95^{\circ} \mathrm{C}$ & $10 \mathrm{~min}$ & $1 \mathrm{X}$ \\
2. & Denaturation & $95^{\circ} \mathrm{C}$ & $45 \mathrm{sec}$ & $35 \mathrm{X}$ \\
3. & Annealing & $52^{\circ} \mathrm{C}$ & $45 \mathrm{sec}$ & \\
4. & Extension & $72^{\circ} \mathrm{C}$ & $75 \mathrm{sec}$ & $1 \mathrm{X}$ \\
5. & Final Extension & $72^{\circ} \mathrm{C}$ & $5 \mathrm{~min}$ & 1 \\
6. & Cooling & $4^{\circ} \mathrm{C}$ & $5 \mathrm{~min}$ & \\
\hline
\end{tabular}

Table 4: Cycling conditions of PCR for amplification of Sarcosystis tenella and Sarcosystis arieticanis using internal primers

\begin{tabular}{llccc}
\hline No. & Step & Temp & Time & Cycle \\
\hline 1. & Polymerase activation & $95^{\circ} \mathrm{C}$ & $10 \mathrm{~min}$ & $1 \mathrm{X}$ \\
2. & Denaturation & $95^{\circ} \mathrm{C}$ & $45 \mathrm{sec}$ & $35 \mathrm{X}$ \\
3. & Annealing & $51^{\circ} \mathrm{C}$ & $45 \mathrm{sec}$ & \\
4. & Extension & $72{ }^{\circ} \mathrm{C}$ & $1.15 \mathrm{~min}$ & $1 \mathrm{X}$ \\
5. & Final Extension & $72{ }^{\circ} \mathrm{C}$ & $5 \mathrm{~min}$ & 1 \\
6. & Cooling & $4{ }^{\circ} \mathrm{C}$ & $4{ }^{\circ} \mathrm{C}$ & \\
\hline
\end{tabular}

\section{Results}

Grossly the muscles of sheep diaphragm appeared pale, white to gray in color with white streak and no macroscopic cysts were observed. The histological examination of diaphragm muscles of sheep revealed presence many sarcocysts with different size, shape (oval and spherical) and blue in color which embedded in the muscle fibers with marked dispersing oedema and sever fragmentation of muscle fibers especially nearing the cysts, some of sarcocysts were ruptured and released bradyzoites in the surrounding tissues (Figure 1).

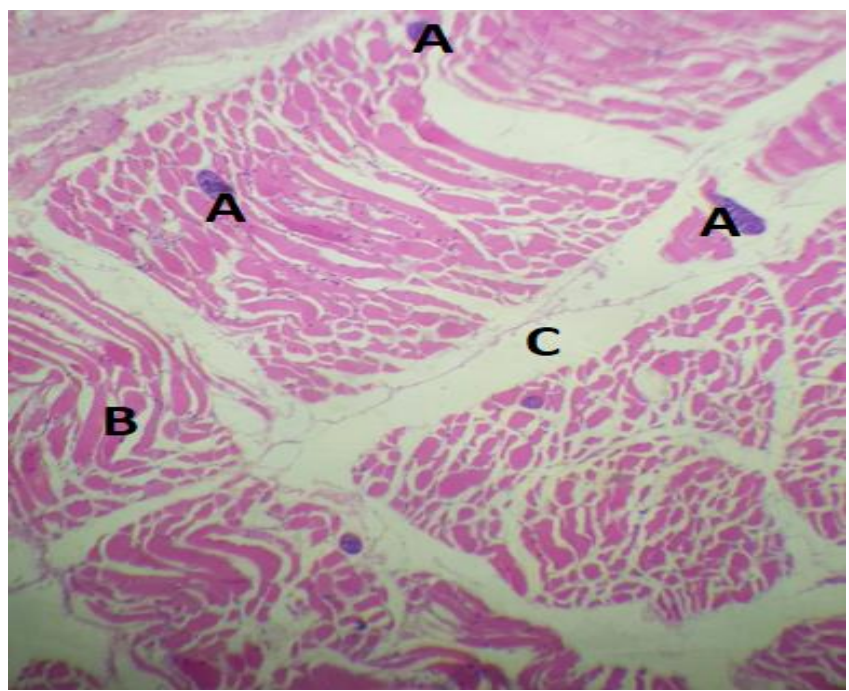

Figure 1: Presence of sarcosystis in diaphragm muscles with different shapes and sizes (A), sever distraction of muscle fibers (B) and edema between muscle fibers (C). H\&E (145X).
Obvious Zenker's necrosis of myocytes with slightly cellular infiltration of inflammatory cells especially eosinophils monocytes and macrophages, were seen in the tissue (Figure 2).

Activation of fibroblast between muscle fibers, so the normal architecture was replaced by fibrous tissue (Figure 3 and 4). Masson's trichrome considered special indicator stain for collagen fibers and it is intensity depended on the ferocity and prolong infections (Table 5), so the fibrotic lesions rich with collagen fibers take blue in color (Figure $5-7)$.

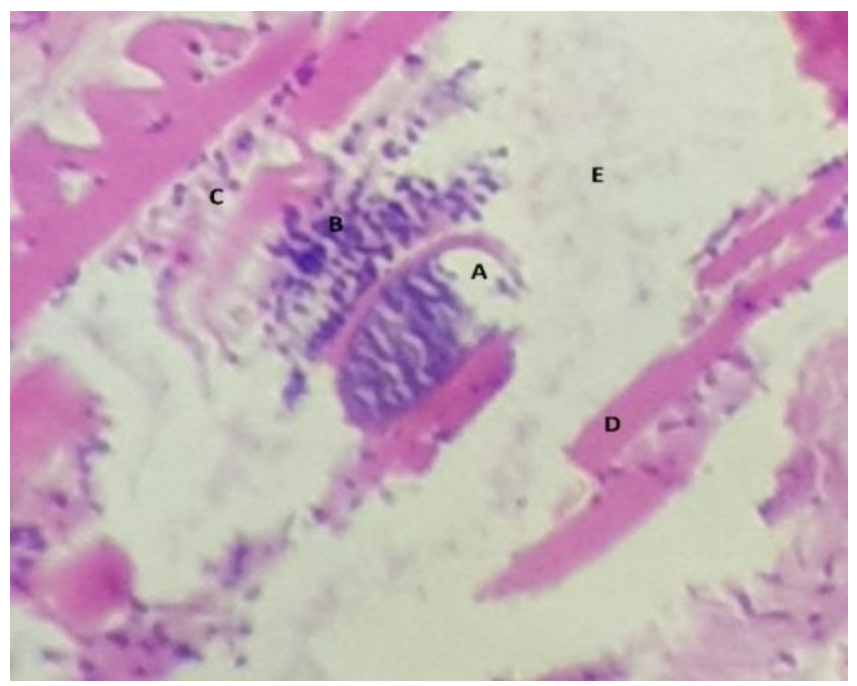

Figure 2: Presence of ruptured sarcosystis (A), distribution of bradyzoites in interstitial tissue (B), infiltration of mononuclear inflammatory cells $(\mathrm{C})$, Zenker's necrosis of myocyte (D) and edema between muscle fibers (E). H\&E (240X). 
Table 5: Lesions and grade of collagen intensity in the affected muscles

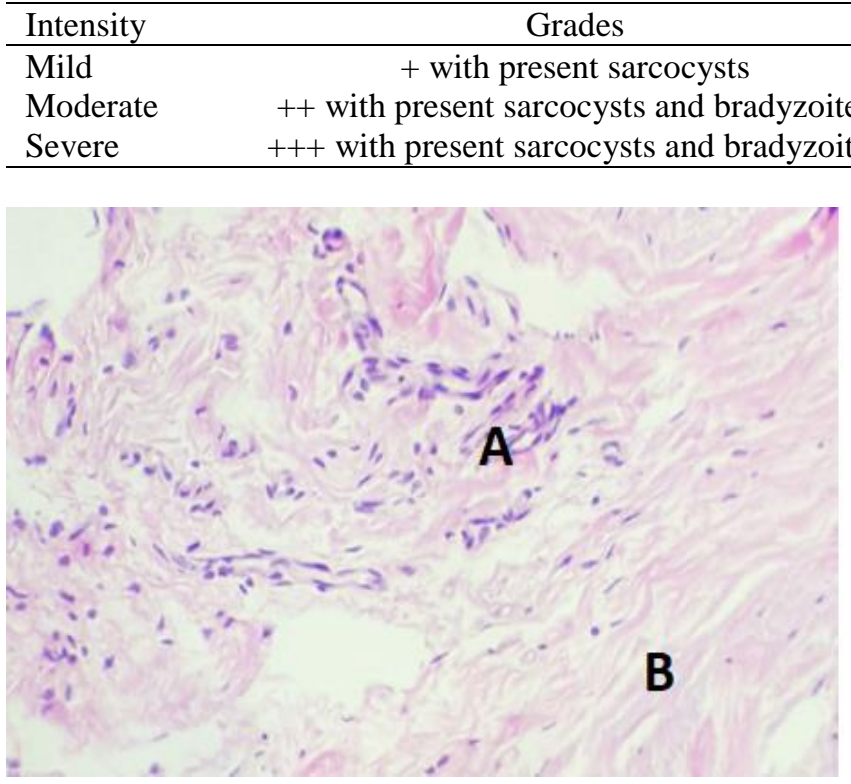

Figure 3: Proliferation of fibroblast (A) with presence of fibrous tissues (B). H\&E (240X).

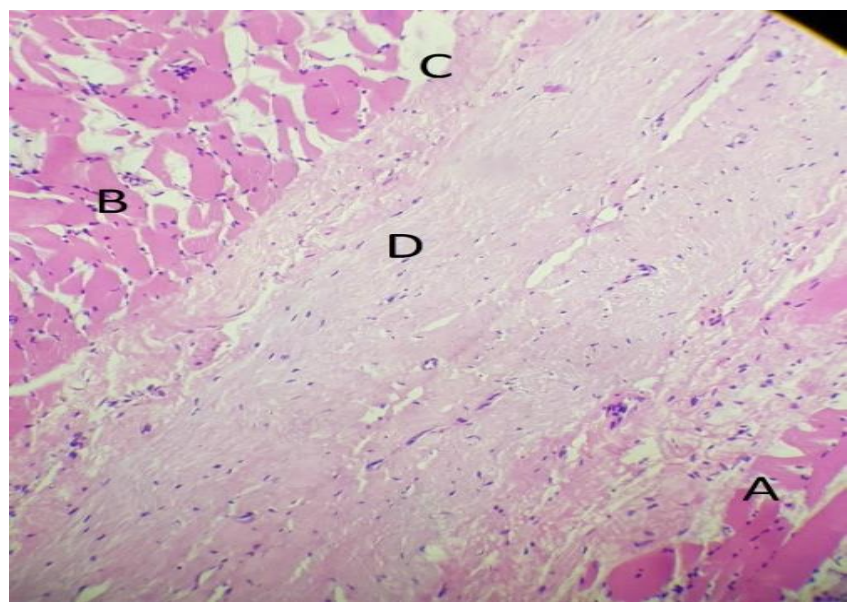

Figure 4: Presence of Zenker's necrosis in myocytes (A), atrophy (B), edema (C) and fibrosis (D). H\&E (220X).

The results of the molecular analysis using the nPCR technique showed the diagnosis of Sarcosystis tenella in 11 samples of the diaphragm muscles of sheep, which were positive by microscopy, using the external and internal primers and the multiplication bands appeared on the agarose gel of $1.5 \%$ concentration, the reaction product was $800 \mathrm{bp}$ and $500 \mathrm{bp}$ (Figure 8 and 9) Whereas, the results of the molecular analysis using the external and internal primer of Sarcosystis arieticanis were negative in the affected diaphragm muscles, as no bands were observed on the $1.5 \%$ agarose gel.

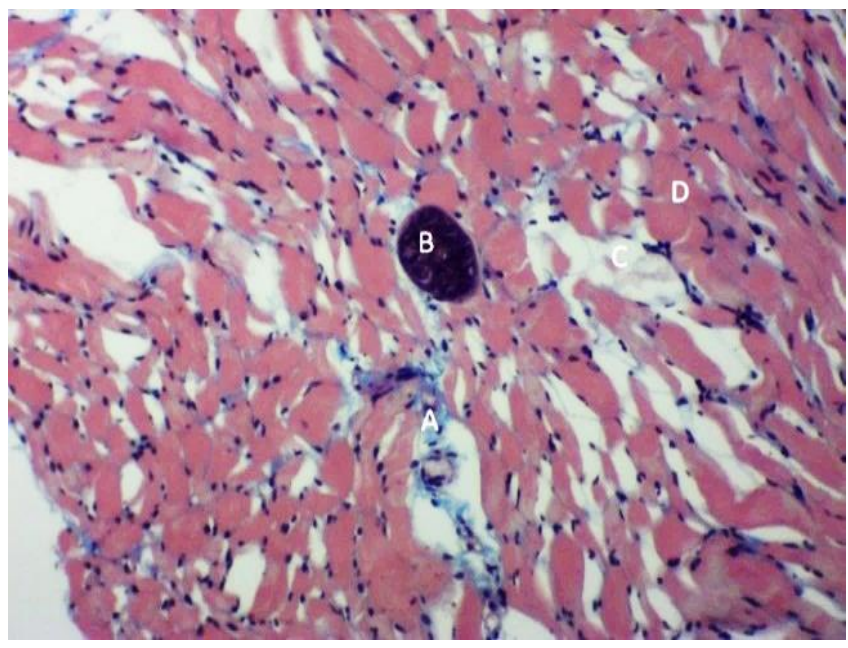

Figure 5: Mild deposition of collagen fiber take blue in color (A), presence of sarcosystis (B), edema between muscle fibers (C) and Zenker's necrosis of myocyte (D) and + Masson's trichrome. H\&E (140X).

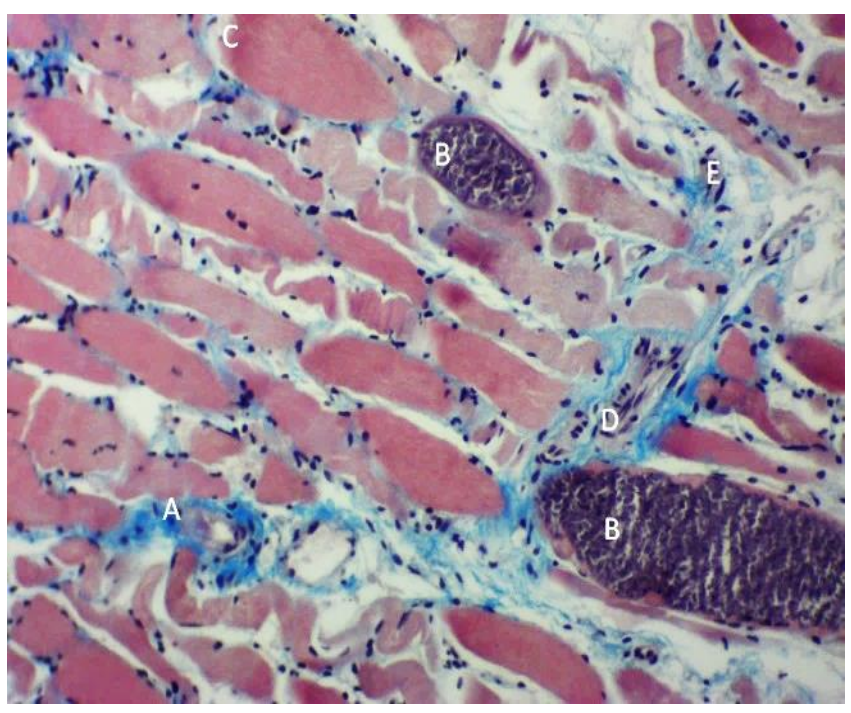

Figure 6: Moderate proliferation of collagen fibers take blue in color (A), presence of sarcosystis between muscle fibers (B), Zenker's necrosis of myocyte (C), infiltration of mononuclear inflammatory cells (D) presence of bradyzoites between muscle fibers (E) and ++ Masson's trichrome (165X). 


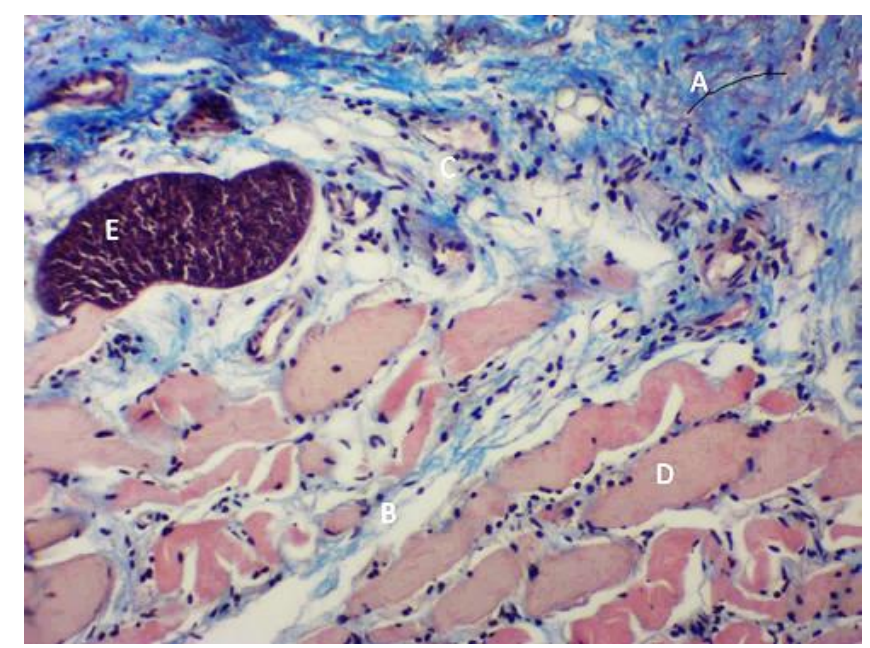

Figure 7: Heavy proliferation of collagen fibers which take blue in color (A), edema between muscle fibers (B), infiltration of inflammatory cells (C), Zenker's necrosis of myocyte (D) and presence of sarcosystis (E) +++ Masson's trichrome (160X).

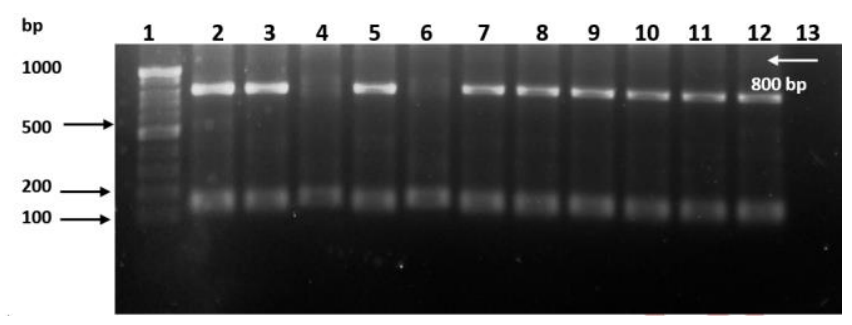

Figure 8: Nested polymerase chain reaction of Sarcosystis tenella (external primers). Well 1 represent 100 bp DNA marker. Wells 2-12 are positive samples, and well 13 negative control.

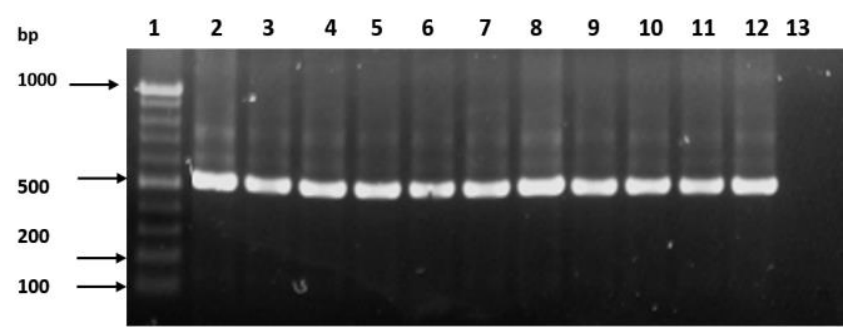

Figure 9: Nested polymerase chain reaction of Sarcosystis tenella (internal primers). Well 1 represent 100 bp DNA marker. Wells 2-12 are positive samples, and well 13 negative control.

\section{Discussion}

Sarcosystis was considered as the most important disease that causes economic losses for meat producing and packing industries, through its effects on morphological and quality of meat which in turn has a negative impact on public health. In our study the affected muscles appeared white and pale in color, this result was agreement with the result of Sun et al. (14).

The histopathological changes of diaphragm muscles represented by the presence of sarcocysts were ruptured and degenerated. The rupture of cyst may be happened due to a host immune reaction or by over distention that occur during the development or as a result of accumulation of metabolic product and cytotoxin that enhanced osmotic pressure and crossing of fluid in to the cyst which become weakened and then ruptured (15), so that the contents of the rupture cyst (bradyzoites and toxins) into the surrounding tissue cause damage and massively infiltration of inflammatory cells specially eosinophils, macrophages,lymphocytes, monocytes and occasionally giant cells at the site of lesion $(16,17)$. These result supported the theory involved the antigenic effects of Sarcosystis have a significance role in activation of immune response then development of eosinophilic myositis $(5,18)$. The muscle necrosis and atrophy observed in this study, so the toxic effects of toxins cause loss of muscle its integrity, rapid utilization of glycogen and accumulation of lactic acid that lead to change in protein structure and subsequent unregulation of calcium flow, followed by increase of cytoplasmic calcium which cause activation of protease and hydrolytic enzymes that induce further muscle damage (19). On the other hand, sarcocyst press on muscle for a long time lead to loss of its mass and then atrophied (18).

Trichrome showed proliferation of collagen fibers stained with blue in color. Connective tissue redesigning is an important and significant stage for muscle regeneration. After the muscle injuries a gab is formed between the muscle fibers and filled with inflammatory cellular debris, so the late in elimination of these remnants and the continuous irritation by sarcosystis lead to activation of fibroblasts and to secrete chemical agents as transforming growth factor-beta1 (TGF-B1) Which have the ability to stimulate the proliferation of fibroblasts subsequently production of collagen fiber (20-22). The intensity of positive reaction of masson's trichrome maybe depend on the ferocity and prolong of infection (23).

The nPCR analysis showed 11 samples of diaphragm muscles appeared positive for microscopic sarcosystis cysts and the microscopic cysts related to species of Sarcosystis tenella only and this species responsible of grossly and histopathological changes. This result may be related to the type and size of the sample used in this study, and this is consistent with Ali et al. (24) in Baghdad province/ Iraq, and da Silva et al. (25) in Brazil, while Pipia et al. (13) referred to diagnosis two microscopic species of Sarcosystis tenella and $S$. arieticanis in heart samples of sheep in Italy by using nested PCR with prevalence 95.5\%, 17.8\% respectively. Oryan et al. (2) showed that the high prevalence of microscopic species of Sarcosystis can have a significant impact on sheep productivity through its negative effect on the weight and growth of sheep as well 
as the high economic losses resulting from abortion. Anja et al. (26) indicated that the diagnosis of Sarcosystis in animals is limited, given that the traditional diagnostic methods based on the detection of specific Sarcosystis antibodies are only genus specific and cannot distinguish between sarcosystis species, in addition to which most of these methods appear good sensitivity to the later stages of the disease, therefore, the diagnosis for acute sarcocystosis was mainly based on postmortem examination. Here, molecular tools are the best diagnostic methods used for the detection of the species of Sarcosystis and in nested PCR assays, the unique small ribosomal RNA gene sequences of the $S$. tenella and S. arieticanis subunit are used.

\section{Conclusion}

This study concluded demonstration the microscopic species of Sarcosystis tenella parasite in diaphragm muscle of sheep by using microscopy and nested PCR associated with the characteristic histopathological changes in diaphragm muscle included, Zenker's necrosis and intense infiltration of inflammatory cells. With the formation of fibrous tissue whose intensity was measured (mild, medium and intense) by using the Masson's trichrome stain.

\section{Acknowledgments}

The authors thanks College of Veterinary Medicine, University of Mosul, to supports this research.

\section{Conflict of interest}

The authors declare that there are no conflicts of interest regarding the publication of this manuscript.

\section{References}

1. Metwally DM, Al-Damigh MA, Al-Turaiki IM and El-Khadragy MF. Molecular characterization of Sarcosystis species isolated from sheep and goats in Riyadh, Saudi Arabia. Animals. 2019;9:256. DOI: 10.3390/ani9050256

2. Oryan A, Moghaddar N, Gaur SNS. The distribution pattern of Sarcosystis species, their transmission and pathogenesis in sheep in Fars province of Iran. Vet Res Commun. 1996;20:243-253. 10.1007/BF00366922

3. Heckeroth AR, Tenter AM. Development and validation of speciesspecific nested PCRs for diagnosis of acute sarcocystosis in sheep. Int J Parasitol. 1999;29:1331-1349. DOI: 10.1016/S0020-519(99)00111-3

4. Alhayali NS, Hasan MH, Al-Mallah KH. Natural heavy infection with immature sarcocysts of Sarcocytis spp. in sheep in Mosul city: A case report. Iraqi J Vet Sci. 2020;34(2):373-376 DOI: 10.33899/ijvs.20110

5. Wouda W, Snoep JJ, Dueby JP. Eosinophilic myositis due to Sarcosystis hominis in a beef cow. J Comp Pathol. 2006;135:249-253. DOI: $10.1016 /$ j.jcpa.2006.07.004

6. Bruschi F, Chiumiento L. Trichinella inflammatory myopathy: Host or parasite strategy?. Parasit Vectors. 2011;4:42. DOI: $\underline{10.1186 / 1756-}$ 3305-4-42

7. Vangeel L, Houf K, Geldhof P, Nollet H, Vercruysse J, Ducatelle R, Chiers K. Intramuscular inoculation of cattle with Sarcosystis antigen results in focal eosinophilic myositis. Vet Parasitol. 2012;183:224230. DOI: $\underline{10.1016 / \mathrm{j} . v e t p a r .2011 .07 .048}$
8. Kimura T. Eosinophilic myositis resulted from Sarcosystis infection in prime marbled beef of Japanese black cattle. Vet World. 2011;4(11):500-502. DOI: 10.5455/vetworld.2011.500-502

9. Do SH, Jeong D, Chung J, Park J, Yang H, Yuan D, Jeong k. Eosinophilic myositis in a slaughtered Korean native cattle. J Vet Sci. 2008;9(4):425-427. DOI: $10.4142 / \mathrm{jvs} .2008 .9 .4 .425$

10. Al-Haaik A. A gross anatomical and histological study of pancreas in adult Kestrel(Falco tinnunculus). Iraqi J Vet Sci. 2019;33(2):175-180. DOI: $10.33899 /$ ijvs.2019.162960

11. Ibrahim SM, Handool KO, Abdul AA, Abu J, Yusof SM, Ibrahimm M, Yusof L. Histological evaluation of the possible role of $\mathrm{Na}+/ \mathrm{H}+$ entiporter and anion exchanger in endochondral ossification activities of secondary bone healing in rats. Iraqi J Vet Sci. 2020;34(2):233-240. DOI: 10.33899/ijvs.2019.125832.1165

12. Al-Mahmood SS, Qadhi AA, Ajeli RA, Alkattan L. Mixed thymic tumor in a rooster: gross and histological features. Iraqi $\mathrm{J}$ Vet Sci. 2019;33(2):201-204. DOI: $\underline{10.33899 / \text { ijvs.2019.125536.1058 }}$

13. Pipia AP, Varcasia A, Zidda A, Dessì GA, Panzalis RA, Tamponi CA, Marrosu RB, Tosciri GA, Sanna GA, Dore FA, Chiesa FC, Scala AA. Cross-sectional investigation on sheep sarcosporidiosis in Sardinia, Italy. Vet Parasitol Reg Stud Reports. 2016;3-4:13-17. DOI: 10.1016/j.vprsr.2016.05.004

14. Sun H D, Da_Hee J, Jae_YC,Jin_KP,Hai-JY, DongWY and Kyu S J. Eosinophilic myositis in a slaughtered Korean native cattle. J Vet Sci. 2008,9(4):425-427. DOI: $10.4142 /$ jvs.2008.9.4.425

15. Jensen R, Alexander F, Dahlgren RR, Jolley WR, Marquqardt WC, Harris CW, Hoffmann GA, Troutman RS, Hoff RL, Jones RL, Collins JK, Hammar DW, Carvans RL. Eosinophic myocitis and muscular Sarcosystis in the carcasses of slaughtered cattle and lambs. Am J Vet Res. 1986;47:587-593. DOI: $\underline{10.1177 / 0300985819891257}$

16. Joythisree CH, Venu R, Smatha V, Malakondaiah P, Ayulu VC. Prevelance and macroscopic studies of Sarcosystis infection in naturally infected water buffaloes (Bubalus bubalis) of Andhra Pradesh. J Parasit Dis. 2017;41 (2) :476-482. DOI: 10.1007/s12639016-0832-z

17. Woada J, Snoep J, Dubey P. Eosinophilic myositis due to Sarcoystis hominis in a beef cow. J Comp Path. 2006;35:249-253. DOI: 10.1016/j.jcpa.2006.07.004

18. El-Shanawang EE, Nassar, Ata EB. Detection of humoral and cellular immune responses in buffaloes naturally infected with sarcocytisis with risk factor assessment. Acta Vet Beograd. 2019;69 (3) :275-289. DOI: 10.2478/acve-2019-0023

19. Laumonier T, Menetrey J. Muscle injuries and strategies for improving their repair. J Exp Orthop. 2016;3:1-9. DOI: 10.1186/s40634-016-0051-7

20. Sierra E, Espinosa A, Fernandez A, Daiz J, Suarez C, Arblo M, Sierra MA, Herraez P. Muscle pathology in free-ranging stranded cetaceans. Vet Pathol. 2017;54 (2) :298-311. DOI: 10.11770300985816660747

21. John BM, Peter JD. Muscle continuous injury and myositis Ossificans traumatica. Clin Ortho Res. 2002;403:S110-S119. DOI: 10.1097/00003086-200210001

22. Valinezhad A, Oryan A, Ahmadi N. Sarcosystis and its complications in camels (Camelus dromedarius) of eastern provinces of Iran. Korean J Parasitol. 2008;46 (4) :229-234. DOI: 10.3347/kjp.2008.46.4.229

23. Botelho MC, Oliveira PA, Vieira P, Delgado ML, Lourenço L, Lopes C, Machado JC, Correia JM. Granulomatous-like immune reaction and hepatic fibrosis induced by Schistosoma haematobium immature worms. Virulence. 2010;1 (3) :123-129. DOI: 10.4161/viru.1.3.11348

24. Ali AI, Hasanhatthot A, Alilateef F. Molecular identification of microscopic cysts of sarcosystis in sheep in Baghdad Province. Int $\mathbf{J}$ Adv Res Biol Sci. 2016;3 (11) :200-205. DOI: 10.22192/ijarbs

25. da Silva RC, Su C, Langoni H. First identification of Sarcosystis tenella (Railliet, 1886) Moule, 1886 (Protozoa: Apicomplexa) by PCR in naturally infected sheep from Brazil. Vet Parasitol. 2009;165:332-6 DOI: $10.1016 /$ j.vetpar.2009.07.016

26. Anja R, Astrid H, Tenter M. Development and validation of speciesspecific nested PCRs for diagnosis of acute sarcocystiosis in sheep. Inter J Parasitol. 1999;29 (8) :1331-49. DOI: $\underline{10.1016 / \mathrm{s} 0020-7519 \text { (99) }}$ $\underline{00111-3}$ 
الإم arieticanis

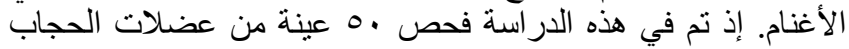

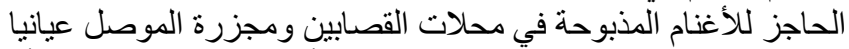

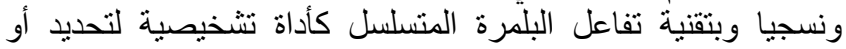

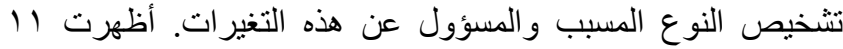

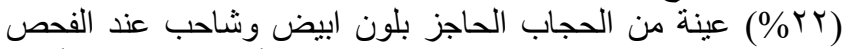
العياني في حين تميزت الآفات النسجية بوجود الكين أكياس الطفيلي بأعداد الطياد

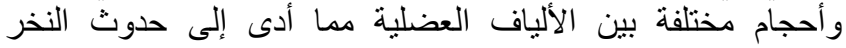

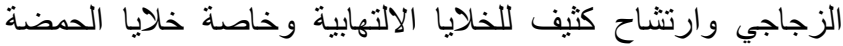

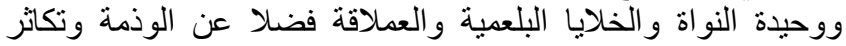

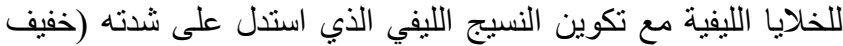

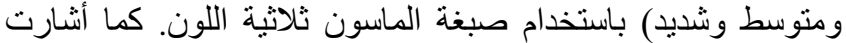

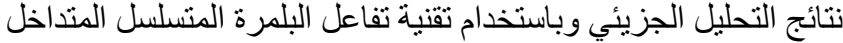
أن هذه الأكياس المجهرية المشخصة تعود للنوع كarcosystis tenella

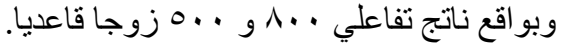

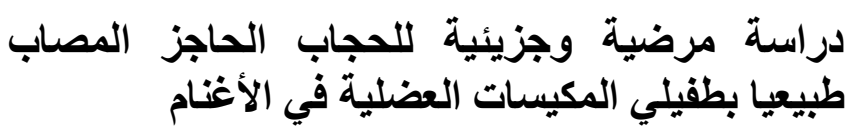

إيناس شيت مصطقى'، نادية سلطان الحيالي' و إيمان غانم سليمان'

'فرع الأمراض وأمراض الدواجن، ‘َفرع الأحياء المجهرية، كلية

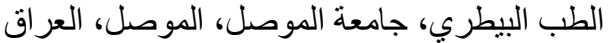

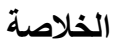





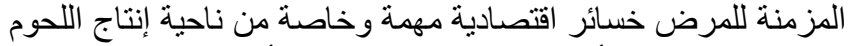
من جراء تكوين الأكياس سواء كانت العين عيانية أم مجهرية في ناهية اليافها

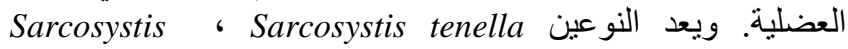

